Schulich School of Law, Dalhousie University

Schulich Law Scholars

Articles, Book Chapters, \& Popular Press

Faculty Scholarship

2015

Offshore Renewable Energy Governance in Nova Scotia: A Case

Study of Tidal Energy in the Bay of Fundy

Meinhard Doelle

Follow this and additional works at: https://digitalcommons.schulichlaw.dal.ca/scholarly_works

Part of the Environmental Law Commons 


\title{
Offshore Renewable Energy Governance in Nova Scotia: A Case Study of Tidal Energy in the Bay of Fundy
}

\author{
Meinhard Doelle* \\ * Meinhard Doelle is a Professor of Law and the Schulich School of Law, Dalhousie \\ University, where he currently serves as the Director of the Marine \& Environmental \\ Law Institute, and as Associated Dean, Research. The research assistance of JD \\ candidate Benjamin Ojoleck is gratefully acknowledged.
}

\section{Abstract}

This article considers the governance approach (including the legislative context, the regulatory system and relevant policy context) to offshore renewable energy developments in Nova Scotia, with a focus on tidal energy in the Bay of Fundy. It explores applicable regulatory processes at the federal and provincial levels as well as the contribution of strategic environmental assessments carried out in 2008 and updated in 2013. The article assesses the ability of the current governance approach to encourage integrated decision making that considers environmental, social and economic factors, such as various environmental impacts and benefits, energy security, economic development opportunities, interaction with other uses.

\section{Introduction}

The Bay of Fundy is a large estuary that separates portions of Nova Scotia and New Brunswick on the Atlantic coast of Canada. The Bay is about $300 \mathrm{~km}$ long and 100 $\mathrm{km}$ wide at its mouth. Due to its shape and location, it experiences extremely high tides, up to 16 meters in the upper Bay. In addition, the Bay of Fundy contains narrow passages that result in ocean currents of over $6 \mathrm{~m} / \mathrm{sec}$ during each tidal cycle. These features combine to provide some of the highest potential for tidal energy development anywhere in the world.

The potential for tidal power development in the Bay of Fundy region of the Atlantic coast of Canada has been recognized for decades. Not surprisingly, there have been previous attempts to develop offshore renewable energy. In the 1980s, barrage based tidal power technology was piloted in Annapolis Royal, Nova Scotia. A combination of technical, economic and environmental concerns identified as a result of this pilot project prevented any large-scale development of the resource at that time. ${ }^{1}$ In recent years, offshore renewable energy has become of interest again. Much has changed since the efforts in the early 1980s.

1 See, for example, M. Conley, G. Daborn, eds., Energy Options for Atlantic Canada, (Halifax, Formac Publishing, 1983). 
There have been considerable changes in the technologies considered since previous efforts in the 1980s. Pilot projects underway around the world are using new, open turbine technology that is expected to significantly reduce cost and environmental impact. This technology operates on principles similar to a wind turbine, except it is anchored or otherwise secured on the seabed in tidal waters. These turbines are able to take advantage of flows of water in both directions, and offer power in predictable intervals during most of the tidal cycle. ${ }^{2}$



The economics of tidal power have also changed as a result of recent increases and fluctuations in energy prices, and the projections for long-term energy supply and demand. Energy security is becoming a growing concern around the world. The environmental imperative for a switch from traditional non-renewable fossil fuel based sources of energy to renewable, low greenhouse gas emitting energy sources has become a pre-occupation of governments in Canada and the United States. Finally, economic diversification has become critical for Maritime communities significantly dependent on the exploration of dwindling resources and on energy intensive manufacturing ${ }^{3}$.

2 For background information on tidal energy technologies, see AECOM, Tidal Energy: Strategic Environmental Assessment (SEA) Update for the Bay of Fundy, (January, 2014) at 31-46, available online: $<$ www.oera.ca/marine-renewable-energy/strategic-environmental-assessment/ >.

3 One Nova Scotia, "Now or Never: An Urgent Call to Action for Nova Scotians - The Report of the Nova Scotia Commission on Building Our New Economy" (2014) OneNS.ca. Available online: < http://onens.ca/report/>. 
All this adds up to considerable pressure to utilize all sources of renewable energy that are technically and economically within reach. Tidal energy is no exception. Numerous potential developers of tidal energy have been pushing governments in Canada to clarify the rules under which this industry will operate, and to allow pilots to be put into the water to demonstrate the viability of the new technologies. Some developers are already pursuing commercial scale developments. At the same time, utilities are trying to understand how tidal energy will fit into the existing and future energy mix, the capacity of the grid to utilize the power generated, and the role of tidal in meeting increasing demand for greener power. The 2013 SEA estimates the realistic potential for power production in the Bay of Fundy to be in the range of 1.7 gigawatts $(\mathrm{GW})$ of power, with the theoretical potential well in excess of 7 gigawatts. ${ }^{4}$

Although Nova Scotia currently has no deployed in-stream tidal turbines, there are several proposals for turbines to be deployed on a 2015 / 16 timescale. There are four major developers interested in placing turbines at one of the available berths at the Fundy Ocean Research Center for Energy (FORCE): OpenHydro, Minas Energy, Atlantis Resources Corporation and Black Rock Tidal Power.

OpenHydro, a company based out of Ireland and owned by DCNS, partnered with Nova Scotia Power in 2009 to deploy North America's first tidal turbine in the Bay of Fundy. This $1 \mathrm{MW}$, open-centre turbine was soon damaged and rendered out-ofcommission due to the tidal forces in the Bay of Fundy greatly exceeding previous estimates and pushing the blades of the six-metre turbine off the rotor. The base and entire turbine were recovered from the water the following year ${ }^{5}$. OpenHydro has since developed plans for a 4 MW tidal array, consisting of two 16m 2 MW turbines. This array was awarded a berth at FORCE by the NSDOE, and is on schedule to be deployed in 2015 . The turbines are $16 \mathrm{~m}$ tall, and weigh approximately 275 tonnes $^{6}$.

Black Rock Tidal Power, a Halifax company, was awarded a berth at FORCE in March 2014, and will be testing the Triton S36 tidal turbine array7. This array consists of 36 individual three-metre turbines arranged on a horizontal axis, with an energy

4 R. Karsten, "Measuring and Assessing the Tidal Resource" (2013) as cited in AECOM, Tidal Energy: Strategic Environmental Assessment (SEA) Update for the Bay of Fundy, (January, 2014) at 6.2.1.

5 OpenHydro, "Bay of Fundy Tidal Energy Project: 2015-2020+" (2014) Last Accessed July 2, 2014. Available online: $<\mathrm{http}: / /$ www.openhydro.com/download/OPENHYDRO-FUNDY-PROJECT-FACTSHEET.pdf $>$.

6 Fundy Ocean Research Center for Energy, "OpenHydro" (2014) Last Accessed July 2, 2014. Available online: $<$ http://fundyforce.ca/technology/openhydro-nova-scotia-power/>.

7 Nova Scotia Government, "Government Funds Tidal Industry, Welcomes New Players" (2014) Last Accessed July 3, 2014. Available online: <http://novascotia.ca/news/release/?id=20140328006> 
production capacity of $2.5 \mathrm{MW}$. The array will initially start with 16 individual turbines in 2015, and is expected to increase to 36 turbines by $2016^{8}$.

Atlantis Resources Corporation is designing the AR1500 turbine for deployment at FORCE with the help of Irving Shipbuilding and Lockheed Martin. This turbine will have a $1.5 \mathrm{MW}$ rated energy capacity and, at $18 \mathrm{~m}$ in diameter, will be one of the largest single-rotor turbines ever developed ${ }^{9}$. This turbine is scheduled for deployment by 2016/17 after testing is completed in China ${ }^{10}$.

Minas Energy, partnered with Bluewater and Siemens, has proposed a design for a 2MW SeaGen F floating tidal current turbine - the first of its kind in the Bay of Fundy. Minas Energy aims to have this turbine deployed by $2015 / 16^{11}$.

The Digby Neck area of the Bay of Fundy also holds significant potential for tidal energy in NS. Fundy Tidal Inc. has already received COMFITs from the provincial government for three sites totaling almost $3 \mathrm{MW}^{12}$. A project description was submitted to a variety of government agencies, as well as the One Window Committee for the Outer Bay of Fundy Tidal Energy Project in 2011, and mentions several developers as potential berth holders in the Fundy Tidal Inc. location. The four main companies that are being considered are NECI, Nautricity, Tocardo and ORPC ${ }^{13}$.

This paper assesses the overall governance approach currently in place for this emerging new industry in the Bay of Fundy. In considering the governance approach, the paper first considers the existing constitutional and regulatory context. The constitutional context is briefly considered in Part 1. As we will see, the jurisdictional context has not been formally resolved, though there appears to be political acceptance of provincial territorial jurisdiction in the Bay of Fundy.

A number of existing federal and provincial regulatory processes will apply to tidal energy projects; however, there is currently no regulatory process in place

8 TidalStream, “Triton S36 - Force” Black Rock Tidal Power, (2013) Last Accessed July 2, 2014. Available online: <http://www.blackrocktidalpower.com/wp-content/uploads/2013/11/TRITON-S36FORCE-.pdf>

9 Fundy Ocean Research Center for Energy, "Atlantis / Lockheed Martin / Irving Shipbuilding” (2014) Last Accessed July 3, 2014. Available online: <http://fundyforce.ca/technology/atlantis/>.

10 Bruce Erskine, "Atlantis to Test Turbine in China Before Fundy Project" The Chronicle Herald (April 7 , 2014) Available online: $<$ http://thechronicleherald.ca/business/1198657-atlantis-to-test-turbine-in-chinabefore-fundy-project>.

11 Marine Current Turbines, "Siemens, Bluewater and Minas to Install Floating Tidal Current Turbines in Canada's Bay of Fundy” (2014) MCT Ltd. Last Accessed July 4, 2014. Available online:

$<$ http:/www.marineturbines.com/News/2014/04/04/siemens-bluewater-and-minas-install-floating-tidalcurrent-turbines-canadas-bay>.

12 Fundy Energy Research Network, "Digby Neck” (2014) Last Accessed July 2, 2014. Available online: $<$ http://fern.acadiau.ca/briar-island.html $>$.

13 Fundy Tidal Inc. "Regulatory" (2014) Last Accessed July 4, 2014. Available online:

$<$ http://www.fundytidal.com/index.php?option=com_content\&view=category\&layout=blog\&id=19\&Itemi $\mathrm{d}=47>$. 
specifically designed for tidal energy. The federal and provincial regulatory context is considered in Parts 2 and 3 respectively. It is this regulatory framework that government decision makers have had to work with since they were first approached to approve tidal pilot projects around 2005. It has been adapted somewhat in preparation for the industry, but it has not fundamentally changed.

Provincial officials initiated an SEA in 2007 to guide future decision making on whether, where, and under what conditions tidal energy development should be approved. The tidal SEA was carried out without any legal foundation, and with limited federal engagement. It was updated in 2013. It is the role of this SEA in improving decision making for new industries in Nova Scotia that is the focus of Part 4 of this article. The article concludes with an assessment of Nova Scotia's overall governance approach to tidal energy.

\section{The Constitutional Context}

The roles of the provincial and federal levels of government in Canada with respect to tidal energy projects will very much depend on whether the projects are located within the territory of a province or outside. Unfortunately, while international maritime boundaries are relatively well established as a result of the broad acceptance and adoption of the 1982 Law of the Sea Convention, ${ }^{14}$ some provincial maritime boundaries within Canada are still unresolved. In the case of Nova Scotia, a strong legal claim can be made that a portion of the Bay of Fundy is part of the territory of Nova Scotia, but the issue has not been formally settled either through negotiations or litigation. ${ }^{15}$

Where tidal development takes place entirely within the territory of the province of Nova Scotia, both the provincial and federal level of government will have jurisdiction to deal with aspects of tidal energy projects. Provincial laws would apply to the production of electricity, and to certain aspects of its export.

Section 92A (1)(c) of the Constitution Act, $1982^{16}$ provides the basis for provincial jurisdiction over the production of tidal power within the province. It provides that:

92A (1) In each province, the legislature may exclusively make laws in relation to...

141982 Law of the Sea Convention, December 10, 1982, 21 ILM 1261 (1982).

15 For Supreme Court of Canada cases that have considered how to determine the territorial offshore boundaries of Canadian provinces, see Reference re Offshore Mineral Rights of British Colombia [1967] S.C.R. 792 (B.C. Offshore Minerals Reference), Reference Re Bed of the Strait of Georgia and related Areas (Georgia Strait Reference), [1984] 1 SCR 388, and Hibernia Reference [1984] 1 SCR 86 . See also GV LaForest, "Canadian Inland Waters of the Atlantic Provinces and the Bay of Fundy Incident" [1963] 1 Canadian Yearbook of International Law 149, and Edward C. Foley, "Nova Scotia's Case For Coastal and Offshore Resources", (1982) 13 Ottawa Law Review 281-308.

16 Constitution Act, 1982, being Schedule B to the Canada Act 1982 (UK), 1982, c 11. See also s 92A(2), (3), and (4). 
(c) development, conservation and management of sites and facilities in the province for the generation and production of electrical energy.

The province also has jurisdiction over local works and undertakings under s. 92(10), property and civil rights under s. 92(13) and other matters of a local and private nature under s. 92(16). Relevant areas of federal jurisdiction would include navigation and shipping under s. 91(10), marine pollution ${ }^{17}$ and inland and seacoast fisheries under s. 91(12). ${ }^{18}$

As a result, developers of tidal energy within the territory of the province of Nova Scotia have to comply with regulatory requirements at both levels of government. The current federal and provincial regulatory frameworks as they apply to tidal energy are briefly explored in the following sections. ${ }^{19}$

\section{The Federal Regulatory Framework ${ }^{20}$}

Regardless of any claims to provincial territorial jurisdiction in areas with high potential for tidal development, it is clear that the federal government does have jurisdiction over aspects of tidal power development. Federal jurisdiction over navigation, fisheries, and inter-provincial undertakings are obvious examples. As a result, a number of federal actors will be involved in Fundy tidal power development decision making, most notably the Canadian Environmental Assessment Agency, the National Energy Board, the Department of Fisheries and Oceans, Environment Canada, Transport Canada and Natural Resources Canada. The following is a brief overview of federal regulatory regimes that are most relevant, although other federal legislation would apply depending on the circumstances. ${ }^{21}$

\section{The Fisheries Act $[F A]^{22}$}

17 As established by the SCC under POGG in $R$ v Crown Zellerbach Ltd., [1988] SCJ No 23, [1988] 1 SCR 401.

18 For a more detailed discussion of jurisdictional considerations for tidal energy development in the Bay of Fundy, see M. Doelle et al, "The Regulation Of Tidal Energy Development Off Nova Scotia: Navigating Foggy Waters" (2006) 55 UNB Law Journal 27, at 34

19 The developer will have to be given some form of property right to develop tidal in a given area to the exclusion of others and to install its equipment. For a discussion of this issue, see M. Doelle et al, "The Regulation Of Tidal Energy Development Off Nova Scotia: Navigating Foggy Waters" (2006) 55 UNB Law Journal 27 at 42.

20 This section is an updated version of the author's contribution to a regulatory summary in M. Doelle et al, "The Regulation Of Tidal Energy Development Off Nova Scotia: Navigating Foggy Waters" (2006) 55 UNB Law Journal 27, at 49

21 An example would be the disposal of waste produced during the construction phase of a tidal project, which would require a "Disposal at Sea" permit under s. 127 of the Canadian Environmental Protection Act, SC 1999, c 33, and the Regulations Respecting Applications for Permits for Disposal at Sea,

SOR/2001-276 and Disposal at Sea Regulations, SOR/2001/275.

22 Fisheries Act, RSC 1985, c F-14, as amended by Jobs, Growth and Long-term Prosperity Act, SC 2012, c 19, ss 132-156. 
Certain provisions of the Fisheries Act, administered by the Department of Fisheries, will be triggered in case of impact on fish or fish habitat, and in case of water pollution resulting from the construction, operation and decommissioning of tidal projects. A tidal project may trigger s.35(1) which contains a general prohibition against "serious harm" to fish, defined in s.2(2) as death to any fish, or permanent alteration or destruction of any habitat. Although s.35(1) generally prohibits serious harm to fisheries, s.35(3) allows the Minister to pass regulations exempting specified works, undertakings or activities from this prohibition. Furthermore, section 35 aims to prevent serious harm to fish only if they are part of a recreational, commercial or Aboriginal fishery, or are fish that support such a fishery. This version of section 35 only recently came into force, so there is no case law to date on its application. A tidal project could also trigger section 36(3) if in the course of constructing, operating or decommissioning the project a deleterious substance is deposited into water frequented by fish. The deposit of certain deleterious substances can be permitted by regulations under s.36(4). Finally, s.37 allows the Minister to require the submission of certain information in case of serious harm to fish, or in case of a deposition of a deleterious substance in water frequented by fish. ${ }^{23}$

\section{The Canadian Environmental Assessment Act [CEAA] ${ }^{24}$}

CEAA, administered by the Canadian Environmental Assessment (CEA) Agency, has the potential to apply to some tidal energy project in the Bay of Fundy. Its actual application will depend on the size and nature of the proposed project, the exercise of discretion by the CEA Agency and the federal Minister, as well as the application of the provincial EA process to the project. ${ }^{25}$

The application of the CEAA is limited to projects. Projects are defined to include any project included in the designated project regulation. The threshold for instream tidal projects is $50 \mathrm{MW}$ and for other tidal projects, such as tidal lagoons, it is $5 \mathrm{MW}$. Certain expansions of existing facilities, depending on the size of the original facility and the scale of the expansion, are also designated projects under the regulations. Not all designated projects require an assessment under CEAA. Rather, there is ultimately broad discretion to determine on a case-by-case basis whether an assessment of a project is required ${ }^{26}$.

\footnotetext{
23 Fisheries and Oceans Canada, Fisheries Protection Policy Statement, (Ottawa: Fisheries and Oceans Canada, 2013). Available online: $<$ http://www.dfo-mpo.gc.ca/pnw-ppe/pol/PolicyStatementEnoncePolitique-eng.pdf $>$.

24 Canadian Environmental Assessment Act, 2012, SC 2012, c 19, s 52 [CEAA]. 25 Regulations Designating Physical Activities, SOR/ 2012-147.

26 The FORCE site in the Bay of Fundy, in addition to being federally reviewed under CEAA, underwent a provincial environmental assessment process in 2009 , and was approved later that year by both authorities. Information about the EA process can be found on the FORCE website at:

$<\mathrm{http}$ ://fundyforce.ca/monitoring-and-research/enviromental-assesment/> .
} 
There are two process options under CEAA, standard assessments and panel reviews. Legal requirements for standard assessments are limited; the process is designed to be flexible and efficient. There are opportunities for substitution and equivalency with provincial EAs, making it unlikely that there will be standard assessments of projects subject to a provincial EA. The standard assessment is the default process option; panel reviews are carried out at the discretion of the Minister. Panels are independent and have to conduct public hearings. CEAA provides for joint panel reviews with other jurisdictions.

\section{The Species At Risk Act [SARA] ${ }^{27}$}

SARA, under the shared responsibility of Environment Canada and the Department of Fisheries and Oceans, applies to all federal land as defined in the Act, including the territorial sea and internal waters of Canada. ${ }^{28}$ SARA is designed primarily to protect listed species on federal lands. It does so through general prohibitions against activities harmful to species listed under section 15 as extinct, extirpated, endangered, threatened or of special concern, in combination with more proactive recovery strategies. The listing process and the general prohibitions associated with it work in combination with a permitting process that can override the general prohibition for certain activities.

Listed species that potentially could be affected include the Blue Whale (Atlantic Population), North Atlantic Right Whale, Fin Whale, Great White Shark, Harbour Porpoise, Leatherback Seaturtle, Piping Plover (Charadrius melodus), Atlantic Salmon, Peregrine Falcon (anatum subspecies), Northern Wolffish (Anarhichas denticulatus) and Spotted Wolffish (Anarhichas minor). ${ }^{29}$ Depending on jurisdictional issues and the project's technology and implementation, s.32(1), s.33 and s.58 all potentially apply. Section 32 generally prohibits harming or killing of listed species. Section 33 deals with harm to the residence of listed species, and s. 58 seeks to protect critical habitat. SARA essentially requires consideration of any potential impact of a project on listed species, their residences and habitats, and requires projects to avoid negative impacts.

Section 32(1) applies if the construction or operation results in the death, harm, harassment, capture or taking of an individual of a species that is listed as an extirpated species, an endangered species or a threatened species. Section 33 comes into play if the project damages or destroys the residence of one or more individuals of a wildlife species that is listed as an endangered species or a threatened species. Section 58 applies in cases where critical habitat has been identified in a recovery strategy of a listed species. It provides for the protection of critical habitat through a general prohibition in combination with more specific provisions depending on

27 Species At Risk Act, SC 2002, c 29 [SARA].

28 See SARA, s 2(1), definition of "federal land".

29 See online: <http://www.sararegistry.gc.ca>. 
whether the listed species is found in a national park, federal land or provincial or private land.

It should be noted that the critical habitat and residences of all the marine species that could be affected by a Fundy tidal energy project have not yet been identified and some recovery plans do not yet exist. This means that as tidal projects proceed, attention will have to be paid to the ongoing development of recovery plans and the identification of residences and critical habitat.

Finally, depending on the circumstances, proponents may be able to enter into an agreement with the Minister or obtain a permit pursuant to s.73 with respect to activities otherwise prohibited. Section 73 gives the Minister limited discretion to allow activities otherwise prohibited due to their risk to listed species.

\section{The Navigation Protection Act [NPA $]^{30}$}

The NPA, currently administered by Transport Canada, will apply because the Bay of Fundy is a navigable water listed in the Schedule to the Act. Pursuant to s.5, a permit is required for a work that is built or placed in, on, over, under, through or across any listed navigable water. The permitting process under s. 5 involves submitting a proposal to the Minister, along with a fee, at which point the Minister will determine if the project "substantially interferes" with navigable waters, assessing a variety of factors under s.5(4). Factors the Minister may take into account under the new s.5(4) include the characteristics of the navigable water in question, safety of navigation, current or anticipated navigation in the navigable water, impact of the work on navigation, and the cumulative impact of the work on navigation in that navigable water.

\section{The National Energy Board Act [NEBA $]^{31}$}

The National Energy Board (NEB) is generally responsible for energy projects of an interprovincial or international nature. Specific to tidal power projects in the Bay of Fundy, if a project crosses provincial boundaries, extends beyond the territory of a province, or includes an interprovincial (s.58.4) or international (s58.1) power line, a certificate (s.58.16) or permit (s.58.11) must be obtained from the National Energy Board pursuant to Part III.1 of the NEBA. ${ }^{32}$ It is unlikely that the NEBA will apply to the construction and operation of most tidal energy project projects. If infrastructure improvements are needed to export some of all of the electricity generated from the tides of the Bay of Fundy to New England, a certificate of public convenience and necessity would be required. These permits and certificates may be subject to "terms and conditions respecting the matters prescribed by the regulations as the Board considers necessary or desirable in the public interest" (s.58.35). In the issuance of permits the board may consider "the impact of the

30 Navigation Protection Act RSC 1985, c N-22 [NPA].

31 National Energy Board Act, RSC 1985, c N-7 [NEBA].

32 The SCC considered the limits of federal jurisdiction in Westcoast Energy v. Canada (National Energy Board), [1998] 1 SCR 322, 156 DLR (4th) 456. 
construction or operation on the environment" as well as "the effect of the power line on provinces other than those through which the line is to pass" (s.58.14).

Complexities regarding overlapping authority or interests between provincial powers and the NEB have, in some cases, been dealt with through Memoranda of Understanding (MOUs). For example, provincial energy bodies in both Alberta and BC have an MOU with the NEB. ${ }^{33}$ Similarly, the NEB, the Canada-Newfoundland Offshore Petroleum Board (C-NLOPB) and the Canada-Nova Scotia Offshore Petroleum Board (C-NSOPB), together with executives from the Newfoundland, Labrador and Nova Scotia Departments of Energy and Natural Resources Canada (NRCan), have formed the Oil and Gas Administrators Advisory Council (OGAAC) ${ }^{34}$ to efficiently deal with issues in their sector. A cooperative approach in the tidal energy sector can help address some of the complexities in identifying the respective roles of federal and provincial energy agencies and departments, but there are constitutional limits to harmonization through cooperation. ${ }^{35}$

\section{The Provincial Regulatory Framework ${ }^{36}$}

As discussed, the geographic extent of provincial jurisdiction over the Bay of Fundy remains unresolved. It is not surprising therefore, that there are only limited signs that the province of Nova Scotia has applied its regulatory regime below the low water mark in marine waters around Nova Scotia. The Nova Scotia Environment Act, for example, has until recently not been applied to activities in the Bay of Fundy. There is some indication that this is changing. Tidal energy developments, for example, have been added as undertakings requiring approval under the provincial environmental assessment process. ${ }^{37}$

Other provincial laws may apply but no formal steps have been taken to date to clarify their role. Some of the key provincial regulatory provisions that may have relevance for tidal power are briefly summarized below, all with the understanding that their actual application depends on the constitutional issues briefly raised above (i.e. is the area within or outside the province) and decisions at the provincial level to extend their application to marine waters below the low water mark.

33 The NEB - BC MOU is available online: <http:/www.neb-one.gc.ca/clfnsi/rpblctn/ctsndrgltn/mmrndmndrstndng/lgscmmssn2007-eng.pdf $>$. The Alberta MOU is available online: <http://www.neb.gc.ca/clf-nsi/rpblctn/ctsndrgltn/mmrndmndrstndng/lbrtnrgtltbrd200601-eng.pdf>. 34 See Canada Oil and Gas Operations Act, RSC 1985, c O-7, s 5.4

35 See M Doelle et al, "The Regulation Of Tidal Energy Development Off Nova Scotia: Navigating Foggy Waters" (2006) 55 UNBLJ 27 at 42.

36 This section is an updated version of the author's contribution to M. Doelle et al, "The Regulation Of Tidal Energy Development Off Nova Scotia: Navigating Foggy Waters" (2006) 55 UNBLJ 27 , at 45.

37 Environmental Assessment Regulations, OIC 95-220 (March 21, 1995), NS Reg 26/95, as amended up to OIC 2013-19 (January 22, 2013), NS Reg. 18/2013, Schedule A, Section $\mathrm{D}(2)(\mathrm{a})$. 


\section{The Nova Scotia Environment Act [NSEA] ${ }^{38}$}

Part IV of the NSEA requires an environmental assessment for certain tidal energy projects. Tidal energy projects of at least $2 \mathrm{MW}$ are listed as Class I undertakings in Schedule A of the regulations. There are other energy undertakings in the list of Class II undertakings, but they would likely not apply to most tidal power projects. An example would be a hydroelectricity generating facility with a production capacity of over $25 \mathrm{MW}$.

Class I and II undertakings have to be registered with the Minister in accordance with the Environmental Assessment Regulations. No work can be commenced on a project that falls within Class I or II until the Minister has granted an approval following the conclusion of the EA process (s.32(1)). Section 47 of the NSEA comes into play if the undertaking is also subject to the environmental assessment or other review requirements of a municipality or the Federal Government (as discussed below, a likely scenario for this project). Section 47 allows the Minister to enter into an agreement with the other government to carry out a joint assessment.

Part V and VI of the NSEA dealing with approvals and releases will also be applicable. Part $\mathrm{V}$ requires an approval for any activity so designated by regulations. It establishes the process for granting approvals, imposing terms and conditions and for changes to approvals. Part VI prohibits activities that may cause an adverse effect unless authorized by an approval under Part V. These provisions combine to require approvals of listed activities and other activities that may have adverse environmental effects. Most importantly an approval can be used effectively to ensure implementation of any conditions and mitigation measures identified during the EA of a particular project. While tidal power projects would most likely not meet the description of activities currently listed under Part 9 of Division $V$ of the activities designation regulations for approval, the Minister would have the discretion under Division VI, s.29(1), of the regulations to add tidal power projects to the list, likely based upon the size or magnitude of the project, the sensitivity of the site or the use of new technology during the proposed activity.

\section{The Fisheries and Coastal Resources Act [FCRA $]^{39}$}

This Act, which inter alia deals with the approval of aquaculture operations, provides a rare example of the application of provincial laws to marine waters below the low water mark. Depending on the precise location of the tidal resource to be developed, there may be geographic and ensuing conflicts involving existing property interests. At present, licenses or leases to carry on aquaculture are issued by the Minister pursuant to the FCRA (Part V). Under s.52(1)(a) a lease "shall be granted for a specific geographic area...". The initial term of the lease is ten years "with a right of renewal by the licensee, at the Minister's option, for further terms of

38 Nova Scotia Environment Act, SNS1994-95, c 5 [NSEA].

39 Fisheries and Coastal Resources Act SNS 1996, c 25 [FCRA]. 
five years each" [s.52(2)(a)]. By s.51(3) or s.52(2)(g) the lease can be terminated for various unmet conditions.

There is potential for conflicting uses involving aquaculture and tidal projects. Relevant to this are s.52(3) and s.44(3) which both acknowledge the aquaculture lease-holder's exclusive right to the water column and sub-aquatic land described in the license. There does not appear to be a provision considering a circumstance arising during a license term where a grantee would be asked to change the location of the operation. There are provisions allowing the Minister to impose certain conditions and restrictions on a lease (s.56) and for the Minister to terminate a lease in the event of a breach of terms or conditions of the lease (s.52 \& s.58) and for the Minister to decide between two competing aquaculture lease applications, but there is no explicit discussion of Ministerial discretion to move an aquaculture lease in the event of competing interests between aquaculture and other marine interests.

Obviously, more specific data are required in terms of development-friendly tidal power areas and existing aquaculture leases, but this potential conflict may not materialize if tidal energy is developed in areas with high current velocities that are unsuitable for aquaculture projects. Similar potential conflicting uses will have to be explored for other existing and potential uses of the Bay of Fundy, such as fishing, tourism, recreation, biodiversity, and potential for other resource extraction activities.

\section{The Endangered Species Act $[\text { ESA }]^{40}$}

The key obligations under the ESA apply to listed endangered or threatened species. The Act essentially prohibits interference with such species unless specifically authorized in the ESA or through a permit or approval. Sections 13 and 14 of the Act include the key provisions on prohibitions and permits with respect to listed species.

Listed species that may be affected by the use of coastal lands for a tidal power project include the Piping Plover (Charadrius melodus) and two species of flora indigenous to Southwestern Nova Scotia bogs and wetlands - the Thread-leaved Sundew (Drosera filiformis) and the Eastern Mountain Avens (Geum peckii). Consistent with the application of the Act to the low water mark, marine species such as leatherback turtles, right whales and other endangered species found in the Bay of Fundy are not listed. ${ }^{41}$

40 Endangered Species Act SNS 1998, c 11 [ESA].

41 For the most up-to-date list of wildlife species protected under the ESA in Nova Scotia as established by the Species at Risk Working Group (pursuant to s.9), see online: <

http://novascotia.ca/natr/wildlife/biodiversity/species-list.asp $>$ 
Other provincial statutes may also apply depending on where related infrastructure, such as transmission lines or service infrastructure, makes landfall. They include the Provincial Parks Act, the Beaches Act, and the Wilderness Areas Protection Act. ${ }^{42}$

\section{The Energy Resources Conservation Act $[E R C A]^{43}$}

The purposes of this Act suggest that it could be utilized to play a role in the strategic development of Nova Scotia's tidal power resources. The Act aims to regulate and ensure efficient practices in the exploration for and development, production, transmission and transportation of energy resources (s.3(b)); provide for the economic, orderly and efficient development in the public interest of energy resources (s.3(d)); appraise the reserves and production capacities of energy resources (s.3(e)); and appraise the need for energy resources and appraise markets outside the Province for the Province's energy resources (s.3(f)).

It is important to note that Section 3 does claim jurisdiction beyond the low water mark. It states that, "This Act applies to all Nova Scotia lands, which means the land mass of Nova Scotia including Sable Island, and includes the seabed and subsoil off the shore of the land mass of Nova Scotia, the seabed and subsoil of the continental shelf and slope and the seabed and subsoil seaward from the continental shelf and slope to the limit of exploitability". The ERCA authorizes the creation of regulations pertaining to development of energy resources in Nova Scotia, which could include tidal energy. To date this legislative authority has primarily been employed to create regulations for the offshore and onshore oil and gas sector.

\section{The Electricity Act [EA $]^{44}$}

The Electricity Act has changed the landscape of Nova Scotia's electricity sector. First, it authorizes regulations regarding "renewable energy standards" in the form of a Renewable Portfolio Standard (RPS) system. This system mandates electricity providers to supply a certain proportion of electricity generated from renewable energy sources. It includes a target of $25 \%$ by 2015 and $40 \%$ by 2020.45 The regulations include provisions on community feed-in tariffs (COMFIT), and developmental tidal array tariffs as well as tariffs for single devices. Developmental tidal arrays, as defined in s.3 of the regulations, refer to either a single device or multiple devices in a generating facility with a production capacity of over $0.5 \mathrm{MW}$. The tariffs associated with developmental tidal arrays require the generation facility to meet a number of requirements, as set out in s.22(2). These requirements include

42 Provincial Parks Act, RSNS 1989, c 367, the Beaches Act, RSNS 1989, c 32, and the Wilderness Areas Protection Act, SNS 1998, c 27.

43 Energy Resources Conservation Act, RSNS 1989, c 147, s 1 as amended by SNS 2000, c 12, as amended by SNS 2001, c 15 [ERCA].

44 Electricity Act, 2004, SNS c 25 [EA]. 45 Renewable Electricity Regulations, OIC 2010-381 (October 12, 2010), NS Reg 155/2010, as amended up to OIC 2014-26 (January 28, 2014), NS Reg. 14/2014. 
being located in Nova Scotia, interconnecting to the electrical grid, being approved for a feed-in tariff, and meeting the definition of "developmental tidal array" as described in the regulations. Community Feed-In Tariffs generally have more defined requirements, as set out in s.20 of the regulations. Section 20(1) of the regulations and s.4A(8)(a) to (e) of the Act list a variety of approved generators that have access to a COMFIT, such as universities, municipalities, co-operatives, community economic development corporations and subsidiaries of municipalities. The regulations also require the generator to own a generation facility as well as meet all the requirements set out in s.20(3), such as being located in Nova Scotia, and conveying electricity at distribution as opposed to transmission levels, meaning at voltages less than $69 \mathrm{kV}$. Ss. 19 and 21 set out how the tariffs are to be set. Section 28 details the ability of the Minister to approve or reject an application for a feed-in tariff. 46

Once a developer has been approved for a FIT in Nova Scotia, s.32(2) of the Renewable Electricity Regulations requires the developer and NSPI to enter into a power purchase agreement. This agreement can either be crafted from a standard form agreement prepared by the Minister and NSPI or from a unique form agreement, as elaborated on in s.32(1) and (1A). A draft of the standard form agreement is available online. ${ }^{47}$

A 2013 hearing by the NSUARB resulted in the adoption of a proposal from a consulting firm (Synapse Energy Economics Inc.) to develop three separate tidal energy tariff rates in Nova Scotia ${ }^{48}$. A developer now has the choice between the Developmental Tariff path or the Test Tariff path, but not both. Under the Developmental Tariff, developers would have access to the tariff rates for 15 years for a given tidal array, with rates set at $\$ 530$ per Mwh for the first $16560 \mathrm{Mwh}$ produced in a year, decreasing to $\$ 420$ per Mwh produced above the $16560 \mathrm{Mwh}$ per year. The Test Tariff is implemented in two phases. The Phase 1 Test Tariff, available only to single-turbine projects located at FORCE, and lasting for a term of three years, has a rate of $\$ 575$ per Mwh for the first 3300 Mwh produced in a year, decreasing to $\$ 455$ per Mwh afterwards. Once the three-year term on Phase 1 has expired, the developer will have access to Phase 2 test rate, which lasts for a 15-year term. Phase 2 rates apply to either a single unit or an array of turbines, and offer $\$ 495$ per Mwh for the first 16560 Mwh per year, decreasing to $\$ 375$ per Mwh for anything produced after that in a year.

Second, the Act mandated Nova Scotia Power Inc. (NSPI) to develop an Open Access Transmission Tariff (OATT). This was intended to open the Nova Scotia electricity market to more inter-provincial and international import and export, while also allowing "any competitive supplier" to supply electricity to NSPI or one of the six

46 Ibid at s 24A(1)

47 Nova Scotia, "Power Purchase Agreement for Renewable Energy (DRAFT)" Halifax: Dept. of Energy, (2012). Available online: <http://0-fs01.cito.gov.ns.ca.legcat.gov.ns.ca/deposit/b10653478.pdf>

48 Tidal Energy Feed-in Tariffs (Re), 2013 NSUARB 214 (CanLII) 
Municipal electricity suppliers. This means that a tidal project whether privately or publicly owned and operated will be able to sell electricity generated to NSPI or to any of the municipal suppliers, all of whom must comply with the RPS. The OATT was approved by the NSUARB, and came into effect in 2005, while the Electricity Act came into effect in 2007. The OATT is accessible to registered users through the online Open Access Same-time Information System (OASIS) ${ }^{49}$.

In 2013, the government of Nova Scotia passed the Electricity Reform (2013) Act - a bill that amended the Electricity $A c t^{50}$. This Act focuses on the ability of retail suppliers of electricity to sell directly to retail customers. For the purposes of the Act, "retail suppliers" are defined as a person other than NSPI or a municipal utility that is authorized to sell renewable, low-impact electricity. This amendment allows smaller producers of electricity to enter into the market, eliminating the monopoly that NSPI and municipal producers of electricity have in the province.

The Wholesale Market Rules Regulations under the Electricity Act may also affect the development of tidal energy in Nova Scotia ${ }^{51}$. These regulations require all generating facilities in the province to register with the Nova Scotia Power System Operator (NSPSO), and enter into a participation agreement with NSPSO. This participation agreement allows the facility to receive service under the open access transmission tariff. In this regards, any new tidal generating facilities would have to register under these regulations, provided they fit the requirements under the regulations.

\section{The Public Utilities Act [Utilities Act $]^{52}$}

The Utilities Act primarily deals with the procedural activities of the Utility and Review Board (UARB) and its regulatory powers over NSPI. This Act may be implicated in a number of ways depending on the specifics of the construction process, as well as the parties involved. Currently, according to s3B of the Electricity Act, the power of the UARB does not extend to the market for tidal power produced by private producers independent of NSPI. In the context of the UARB rate hearings in 2004, the Board found that the Utilities Act did not authorize the Board to consider the appropriateness of rates offered by NSPI to independent energy producers. ${ }^{53}$ For tidal power in Nova Scotia, this would suggest that the market, not

49 Nova Scotia Power Inc., Open Access Transmission Tariff, (Nova Scotia: NSPI, 2005). Available online: $<$ http://oasis.nspower.ca/site/media/oasis/ApprovedOATT052005.pdf>

50 Bill 1, An Act to Amend Chapter 25 of the Acts of 2004, the Electricity Act, Respecting the Sale of Renewable Energy, 1st session, 62nd General Assembly, Nova Scotia, 2013 (Assented to December 12, 2013).

51 Wholesale Market Rules Regulations, NS Reg 36/2007.

52 Public Utilities Act, RSNS 1989, c 380, [Utilities Act].

53 Rather it is solely concerned with charges to be paid by customers. See Nova Scotia Utility and Review Board, In the Matter of The Public Utilities Act -and- In the Matter of Nova Scotia Power Incorporated and complaints from seven individuals concerning the rates and conditions set out by NSPI in its solicitation for renewable energy under $2 \mathrm{MW}$ (2004). See online:

$<$ http:/www.canlii.org/ns/cas/nsuarb/2004/2004nsuarb118.html> 
the government, currently controls the price to be paid to producers (at least for provincial markets). Given that NSPI is still essentially a vertically integrated monopoly, it controls the price, subject only to UARB oversight as to whether NSPI has paid more than necessary for its power, although some measure of change has occurred in the way of the Electricity Reform Act. Increasing the percentage of renewable energy required under the existing RPS might be a way to influence the price NSPI would be willing to pay for tidal power. If the RSP is sufficiently high that NSPI cannot meet it using wind alone, it may be required to purchase tidal even if the price was higher than wind. One other factor that may influence the amount of tidal energy necessary to fulfill the RSP is the requirement of NSPI to purchase $20 \%$ of the electricity generated at the Muskrat Falls Generating Station under s.6A(2)(c) of the Renewable Electricity Regulations, provided the infrastructure is complete, in normal operation, and the UARB has approved the assessment under the Maritime Link Act. Other factors, such as the predictability of tidal would likely also influence NSPI's choice. An alternative would be to determine a fixed or minimum price for each form of renewable energy. This is generally referred to as the feed-in tariff approach. It would in effect allow the province to set the price to be paid by NSPI for tidal power produced. ${ }^{54}$

\section{The Environmental Goals and Sustainable Prosperity Act [EGSPA] ${ }^{55}$}

The EGSPA sets the overall goal of fully integrating environmental sustainability and economic prosperity through continuous improvement in measures of social, environmental and economic indicators of prosperity. The Act sets more specific targets that are relevant to the development of tidal energy, including goals with respect to greenhouse gas emissions and the use of renewable energy for the generation of electricity. The overall goals and specific targets do not directly translate into decisions on whether, where, when and under what conditions to encourage or permit tidal power development, because they treat renewable energy collectively, but they provide important context for future decisions on this emerging industry.

\section{Pending Marine Renewable Energy (MRE) Legislation}

A working draft of MRE legislation is scheduled to be released in 2014. It is expected to be consistent with the Marine Renewable Energy Strategy and the recommendations in the Fournier Report. A key recommendation is the need for collaboration between federal and provincial authorities to engage in a dialogue to work toward harmonization of legislation, policies and regulations. ${ }^{56}$ This recommendation seeks to reduce the

54 See J Lipp, “Lessons for effective renewable electricity policy from Denmark, Germany and the United Kingdom“" (2007), 35 Energy Policy, 5481-5495.

55 Environmental Goals and Sustainable Prosperity Act, SNS 2007, c 7, as amended by 2012, c 42. [EGSPA]

56 Robert O Fournier, Marine Renewable Energy Legislation - A Consultative Process ('The Fournier Report'), (Nova Scotia: 2011). Available online: $<$ http://www.oera.ca/wpcontent/uploads/2013/05/Fournier-Final-Report.pdf $>$. 
complexity of the regulatory system. To date, an informal One-Window Standing Committee has been used, bringing together representatives from provincial and federal departments. Although the Fournier report concluded that the One-Window committee was an important first step, the Report suggests evolving this approach to keep pace with the increasing rate of development.

\section{The SEA process}

In this section, we consider the role of an SEA carried out in 2007-08 and updated in 2013 in the governance of tidal energy in the Bay of Fundy. The SEA was initiated in 2007 to consider whether, where and under what conditions offshore renewable energy developments should be encouraged and approved in the Bay of Fundy. The review of the SEA process will take place in three stages. The SEA process is first outlined. The outcomes of the SEA are then considered.

The Tidal SEA process was initiated as a result of a request by the Nova Scotia Department of Energy to the Ocean Energy and Environment Research Association (OERA). ${ }^{57}$ OERA is a not-for-profit corporation established in 2006 with funding from the province of Nova Scotia. OERA is a collaboration between the provincial government and academic institutions in Nova Scotia interested in research on the environmental implications of ocean energy development around Nova Scotia. OERA was formally asked to carry out the SEA in April, 2007.

The Minister asked OERA to complete its work on the SEA within 12 months, and with a $\$ 250,000$ budget. The SEA process was placed in the hands of a subcommittee of OERA made up of 15 individuals representing the governments of Nova Scotia, New Brunswick and Canada, fishing and environmental interests, academics with backgrounds ranging from engineering and biology to law, and a retired civil servant. ${ }^{58}$ The SEA process designed by OERA consisted of the following key components:

- An interactive website (www.bayoffundysea.ca).

- A newsletter published regularly throughout the SEA process.

- Informal meetings with stakeholders on request.

- Regular meetings of the OERA subcommittee to guide the process.

- A consultant hired to serve as the "process-lead" for the SEA process.

- Six community forums held in August, 2007 in affected communities.

- Two rounds of participant support funding for community based research.

- A background report prepared by the environmental consulting firm.

- A round table of about 25 interested stakeholders. ${ }^{59}$

57 During the 2008 SEA process, the acronym OEER was also used for the Association. The change resulted from an internal re-organization.

58 OEER, Fundy Tidal Energy Strategic Environmental Assessment: Final Report (Nova Scotia: OEER, 2008) at 5.

$59 \mathrm{Ibid}$, at 5. 
Early efforts to engage Nova Scotians were intended primarily to help identify key issues to be addressed through the SEA process. The main vehicles for identifying issues of concern were the six community forums held in August, 2007 and some informal meetings with key stakeholders. The forums in particular provided important guidance to the OERA subcommittee and the process lead on the values, concerns and priorities of affected communities, and potentially affected industry sectors such as fisheries and tourism. To this end, participants in the forums were asked two questions:

- What information is needed before decisions can be made about whether, where and under what conditions tidal energy should be permitted or encouraged in the Bay of Fundy?

- What information are you aware of that may be relevant to this process?

In parallel with the forums, OERA hired Jacques Whitford, an environmental consulting firm, to prepare a background report on the technologies, the receiving environment, and their potential interaction. The backgrounder was intended to serve as a starting point for the SEA process. As such, it sought to identify the sate of knowledge and encourage participant to consider the implication of the state of knowledge for the SEA process.

Given the short time frame and the limited resources available to carry out the SEA, there clearly was no real opportunity to fill information gaps identified. Some effort was, nevertheless, made to fund efforts by community groups to supplement the information provided through the backgrounder. Topics covered included native fisheries in the Bay of Fundy, how to enable community benefits from tidal energy development, integrated resource management in the Bay of Fundy, research on submerged ice, and the gathering of local and traditional knowledge relevant to the SEA. ${ }^{60}$

The Round Table commenced its work after the conclusion of the community forums. Interests represented on the Round Table include municipalities, fisheries, aquaculture, community development, environmental organizations, tourism, marine transportation, the local power utility and tidal developers. It met a total of seven times between October 2007 and April, 2008. Given the time available, and diversity of interest and perspectives, a surprising level of consensus was reached. At the same time, it must be recognized that the limited time and resources, as well as the size of the round table, made a deeper level of agreement on the substance impossible. As a result, many of the SEA recommendations are general in nature. They will require ongoing engagement of stakeholders to become meaningful and clear, and to ensure that some of the unresolved issues underlying these general recommendations are not forgotten as time passes.

60 For information on the funding program and the results of funded initiatives, see online: < http://www.oera.ca/>. 
Following the conclusion of the Round Table process, the OERA subcommittee prepared the SEA report. The report was submitted to the provincial government on May 1, 2008. A final round of hearings in May of 2008 sought further feedback on this report. OERA submitted a community comment report that summarized the final feedback received by way of follow-up to the SEA report. In July, 2008, the Province released its response to the SEA report. ${ }^{61}$

The province accepted most of the recommendations either explicitly or in principles. This is not surprising given the close connection between the provincial Department and Energy and OERA. The province proceeded to start the work of implementing the 29 recommendations of the report. Key next steps in the development of tidal energy in the Bay of Fundy included the approval of the research facility following an environmental assessment, ${ }^{62}$ the first testing of an instream tidal turbine at the research facility, ${ }^{63}$ and efforts to improve the legislative and regulatory basis for this new industry. ${ }^{64}$

In 2013, the province decided to update the 2008 SEA. It commissioned a private consulting firm, AECOM, to prepare an update to the SEA. AECOM, in coordination with OERA, followed a process similar to the 2008 SEA. It started by updating the backgrounder that had formed the information basis for the 2008 SEA. AECOM struck a round table and held community meetings. It submitted its report to OERA in January of 2014.

\section{SEA Outcomes}

The 2008 SEA report included 29 recommendations to the province of Nova Scotia. The recommendations were supported by all members of the OERA subcommittee and were generally supported by the round table. The following are some of the key recommendations in the 2008 SEA:

- The province should adopt and apply 10 sustainability principles as a framework for decision making on renewable energy development in the Bay of Fundy.

○ Pilot in stream tidal projects should be permitted to proceed carefully and incrementally.

61 Bay of Fundy Tidal Energy: A Response to the Strategic Environmental Assessment, NS Department of Energy (July, 2008) available online: < http://energy.novascotia.ca/resources-and-publications/documentdatabase/>.

62 FORCE Environmental Assessment, (2009) Nova Scotia Environment Website. Available online: $<$ http://www.novascotia.ca/nse/ea/minas.passage.tidal.demonstration.asp $>$.

63 OpenHydro, News Release, "OpenHydro Successfully Deploys 1MW Commercial Tidal Turbine in the Bay of Fundy" (November 17, 2009). Available online: <http://www.openhydro.com/news/OpenHydroPR171109.pdf>.

64 Supra note 51. 
- There should be ongoing consultations and participation in decision-making, and a community participation and benefits strategy should be developed.

- The province should develop new legislation and amend existing legislation to improve the regulation of this industry.

- A research agenda should be developed to fill knowledge gaps.

- Efforts should be made to maximize local benefits from any development of renewable energy in the Bay of Fundy.

- The province should place a high priority on conservation, efficiency and to ensuring that electricity from tidal developments replaces fossil fuel based electricity.

- The capacity of the power grid in Nova Scotia to accept power from tidal power projects needs further study.

- The potential for impacts on other users needs to be considered. The report recommends an integrated approach to resource management in the Bay of Fundy.

The provincial response was generally positive. In addition to responding to the recommendations, the government highlighted the following measures:

- The government committed to providing funding and finding other ways of encouraging the research needed to fill the information gaps identified through the SEA process.

- The province decided to proceed with a demonstration facility for in stream tidal (FORCE) and with a demonstration program for other forms of renewable energy.

- The government committed to remove devices in case of adverse environmental effects.

- The government confirmed the need to ensure compensation agreements are developed with other users of the Bay of Fundy.

- The government confirmed its desire to encourage collaboration with all affected jurisdictions and stakeholders. ${ }^{65}$

The 2013 SEA update included a review of the implementation of the recommendations of the 2008 SEA. It concluded that 26 of the 29 recommendations had been implemented or were in the process of being implemented. Two of the remaining recommendations were dependent on cooperation from other jurisdictions. The most notable recommendation not implemented is the integrated regional planning process. In addition, the commitment for compensation agreements for users affected by tidal developments appears to have been abandoned.

The 2013 SEA update identifies some key developments since the 2008 SEA. It concludes that tidal in stream technology has evolved significantly since 2008. Two distinct scales of development have emerged, a commercial scale intended for

65 Supra note 56, at 5 
power production at the lowest possible cost, and a smaller scale technology designed to meet local power needs. These scales are reflected locally in the efforts of FORCE to encourage commercial scale developments, and the efforts of Fundy Tidal Inc. to deploy smaller units in the Digby Neck area.

Knowledge gaps in terms of the social and environmental impacts largely remain. The Open Hydro unit was not in the water long enough to provide an opportunity to fill knowledge gaps regarding the interaction of the turbines with marine species. The pilots planned for the next few years, both by FORCE and in the Digby Neck area, are expected to help fill some of these gaps. Uncertainty also remains with respect to social and economic benefits, risks and uncertainties associated with tidal developments, and opportunities to maximize these benefits. In addition, the 2013 SEA update identifies the following technical challenges:

1. Sensors and instrumentation: assessing the resource, monitoring the devices, and monitoring environmental effects;

2. Deployment and recovery: installation and maintenance of devices and cables;

3. Subsea electrical grid: to transmit and condition the electricity generated by the devices;

4. Turbines/moorings: the devices and equipment that generate the electricity and maintain the position of that equipment and related infrastructure; and,

5. Cabling and connectors: between the land-based infrastructure and the subsea grid, both for electricity and communications. ${ }^{66}$

The impact of the SEAs on tidal energy governance in Nova Scotia is apparent. One of the most important elements of the 2008 SEA was the constructive engagement by stakeholders. Opportunities for mutual learning were evident during the process. Developers provided valuable insight into conditions for development for a variety of technologies. Members of the fishing industry provided valuable insight into local conditions, particularly some of the high current velocity passages. Other users were able to identify concerns over potential use conflicts. Exchanges on these issues at the round table allowed everyone to develop a better understanding of the range of potentially suitable sites.

It seems clear that the Nova Scotia government has taken the recommendations of the SEA seriously. While much work is still to be done, the SEA has resulted in Nova Scotia being much more prepared for the industry than it was in 2008. More aggressive renewable energy targets, feed-in-tariffs for tidal energy, an operational research facility, a tidal research network, and the expected release of a Marine Renewable Energy Act are all significant steps forward. ${ }^{67}$

66 AECOM, Tidal Energy: Strategic Environmental Assessment (SEA) Update for the Bay of Fundy, (January, 2014) at 58, available online: $<$ www.oera.ca/marine-renewable-energy/strategic-environmentalassessment/ $>$.

67 Ibid at 59. 


\section{Lessons Learned from Tidal Governance in the Bay of Fundy}

This section explores the lessons that can be drawn from the Nova Scotia experience with tidal energy in the Bay of Fundy. One category of observations deals with opportunities to improve tidal energy governance in Nova Scotia, and how other jurisdictions interested in tidal energy can benefit from the experience in Nova Scotia. A second category of observations deals with lessons more broadly on how jurisdictions such as Nova Scotia can develop effective governance approaches for newly emerging industry sectors.

Perhaps the most important general observation with respect to tidal energy governance in Nova Scotia is that the SEA process has provided importance guidance for governments and key stakeholders involved in the development of the industry. The SEA process was an important step forward from past practice in Nova Scotia, as it initiated a proactive approach to developing an effective governance approach.

It is encouraging that the province of Nova Scotia took this more proactive approach to tidal energy. Early indications are that the benefits include constructive relationships with other users of the areas affected by tidal developments, some regulatory coordination and review early in the evolution of the industry, good coordination between development of the industry and research to better understand impacts and risks, and broad public support for the industry.

The tidal SEA process, of course, has had its limitations. It was limited by its ad hoc nature. This limitation is best addressed by providing a clear legislative foundation for SEAs carried out in Nova Scotia. Such legislation, perhaps under the Nova Scotia Environment Act, would establish rules on when an SEA is to be carried out, on the process to be followed, and on the role of the SEA in guiding future decision-making.

A key element of any legislative foundation for SEA is the connection of the SEA to higher and lower tier decision-making. Higher tiers in this regard refer to decision making that goes beyond the tidal energy industry, such as regional planning, economic development at a provincial level, energy planning, etc. SEA legislation should set out clear expectations for how the results of the SEA feed into higher level decision-making, and how changes in high level policy feeds into the SEA. Lower tier decision-making refers to project level decisions in the tidal sector. A legislative foundation for SEA would include clear direction on how the SEA will guide project EAs and regulatory decisions. Federal and municipal involvement in the SEA would be required to maximize the opportunity for proper integration of the SEA into higher and lower tier decision making. However, even integration at the provincial level would significantly enhance the governance approach.

The tidal SEA process was also limited in terms of the time and resources available. Knowledge gaps with respect to the environmental, social and economic 
implications of this industry were identified but generally not filled. A number of issues, such as which approach to tidal energy is most likely to maximize long-term benefits to Nova Scotia (particularly rural development benefits) were identified but not resolved in the 2008 SEA. It is encouraging the see the effort to update the SEA in 2013 , as periodic updates provide the opportunity to track knowledge gaps and ensure adjustments to the governance approach as we learn more about the benefits, impacts, risks and uncertainties associated with tidal energy production. Based on the 2013 update, it appears that some progress has been made, but significant knowledge gaps remain.

For these reasons alone, further implementation and refinement of the SEA will continue to be critical. It has to continue to track knowledge gaps and continue the dialogue on values and priorities and how best to pursue them. For example, the interaction of turbine with marine life remains poorly understood. It remains unclear whether it would be in the best long-term interest of the province to focus on making the Bay of Fundy a testing, research and manufacturing site for tidal technology or on producing energy at a large scale? What are the key economic opportunities associated with the industry? Are they related to the production and use of the energy produced, or are they related to research and manufacturing?

As decisions continue to be made about individual pilot projects, as experience is gained about the technical, social, economic and environmental feasibility of tidal energy, it will be critical that communities continue to feel as informed and as involved as they were at the start in decisions about whether, where and under what conditions tidal energy projects ought to be permitted in the Bay of Fundy. The pilots will play an important role in the decision making process for this new industry. It will be critical that the pilots are utilized to fill in some of the information gaps, particularly gaps in the understanding of the interaction between the various technologies and the receiving environment.

Continuity in terms of transparency of decision-making and public engagement is also critical. It is clear that the tidal SEA in Nova Scotia has developed a new level of trust and expectation in terms of transparency and public engagement in decisionmaking. The constructive relationships developed will be at risk if the expectations are not realized as the sustainability principles developed and other recommendations are applied to individual tidal projects.

The role of government decision makers in the SEA process must be carefully considered. It needs to be designed to ensure independence and credibility of the process on the one hand, and active engagement of key decision makers on the other hand. As with project EAs, early triggering of the tidal SEA was key. An effective way of addressing the challenges identified with the tidal SEA would be to provide a legislative foundation for SEA at the provincial and federal levels. Initially, the legislation will have to retain considerable flexibility to be able to adjust to experience and unforeseen circumstances. As jurisdictions gain experience with SEAs, flexibility should gradually be replaced with legislative guidance. 
The absence of integrated planning in the Bay of Fundy will limit the long-term effectiveness of tidal governance in Nova Scotia. It may be reasonable for purposes of deciding on whether to move ahead with pilot projects to assume the status quo of resource use and management will and should continue. It is more difficult to see how decisions about commercial scale developments can be made in the absence of integrated planning, even with an incremental approach. This means that an integrated planning process for the Bay of Fundy will be critical to the success of tidal energy governance as it moves from pilots to commercial scale developments.

In the end, appropriate decisions about the role of this new industry, and how to maximize long term sustainable benefits to Nova Scotians cannot be made until an integrated management plan is in place for the Bay of Fundy. The main role of an SEA should be to update integrated management plans in light of the evolution of this new industry, not to eliminate the need for integrated planning and management.

Changes are also warranted on the regulatory side. To date, the focus has been on the coordination of existing regulatory requirements for tidal developments in combination with some new regulatory measures to encourage tidal developments, mainly in the form of feed-in tariffs and renewable energy targets. What remains is nevertheless a patchwork of federal and provincial regulatory requirements that seem unnecessarily complex, and that are not carefully designed to meet the goals and priorities set by the SEA. The marine renewable energy legislation that is currently being drafted provides an opportunity to set out the regulatory goals and objectives in legislation and to design an effective, efficient and fair regulatory system that furthers those goals and objectives, rather than the current patchwork that is based on a range of policy objectives that pre-date the emergence of the industry.

The 2008 SEA makes a number of recommendations with in this regard. It proposes that the legislation should encourage the development of marine renewable energy resources in a safe and environmentally sound manner. It should require interested parties to obtain licenses for the rights to develop. Such licenses should be conditional on undertaking activity that will promote timely development. The legislation should provide for immediate disclosure of all environmental information and, after appropriate confidentiality periods, disclosure of technical information related to the resource. The legislation should provide for the Province to receive revenues from the licensing and/or development of the resource and provide opportunities for affected communities to benefit from the development. Finally, the SEA proposes that the legislation provide incentives for the net reductions of greenhouse gases in the Province.

These are all recommendations that should be considered carefully in the design of the pending Marine Renewable Energy legislation. Furthermore, the legislation should set clear regulatory goals and objectives consistent with the conclusions of 
the SEA, be fully transparent to protect the social licence the industry currently enjoys, ensures effective monitoring and research is conducted to learn from the experience, and continues to engage those interested and potentially affected by this industry in the evolution of the regulatory system.

\section{Conclusion}

Tidal energy governance in Nova Scotia is largely a good news story. Through proactive efforts over the past decade, the province seems reasonably well prepared for this emerging new industry. Considerable work, however remains. In particular, it is high time for an integrated planning process for the Bay of Fundy to ensure tidal plays an appropriate role in the sustainable use of the resources the Bay of Fundy has to offer. Furthermore, the current regulatory system is complex, and not designed to further the goals and priorities identified for the industry in the SEA. The pending Marine Renewable Energy legislation in Nova Scotia provides an opportunity to reform the regulatory system at the provincial level. 